\title{
The Research on the Social Integration of the Top Management Team
}

\author{
Lin $\mathrm{Yu}$ \\ Department of Economic Management,Shanghaixingjian Business College , Yuanping Road \\ 55, Jingan District , Shanghai ,China \\ yulin0526@163.com
}

Keywords: top management team, social integration, enterprise performance

\begin{abstract}
Social integration of top management teams is an important condition for sustainable development of enterprises. The article points out that social integration involves social capital integration, emotional conflict integration, the level of information exchange, collective decision-making level and team cooperation, the article constructs a model for how the top management team affect enterprise performance mediated by social integration, makes up for gaps in the theory of the top management team and provides the ideas, methods for the top management team building, training and performance evaluation.
\end{abstract}

\section{Introduction}

The uncertainty of the corporate environment makes it hard for entrepreneurs to turn the tide on their own. In the current crisis, high-performing management teams are the source of competitive advantage. Top managers with high value and scarce and difficult to imitation, is to construct the core competitiveness of sustainable competitive advantage of organization, executives how to effective operation is the key to a team's social integration. Executives as a "social person", has a high rate of return of resources, but executives between heterogeneity, they do not necessarily in the cooperation can maximize each have resources, it is need to improve the level of social integration of the top management team. This paper intends to explore the senior management team of the social integration of this construct, points out that the enterprise should from the social capital, emotional conflicts, information exchange, collective decision-making and team this five aspects to enhance the level of social integration and put forward new research model for senior management team of theoretical research, make up the blank of the senior management team theory, for the senior management team, provide ideas and methods of training and performance evaluation.

\section{Top ManagementTeam of Social Integration Research}

The famous French sociologist gisela dulko, first put forward the construct of "social integration", this is a sociological concept, it is the corresponding category of sociology and social disintegration. American sociologist. parsons incorporated the concept of social integration into his structural functional theory. Dennise M.R ousseau, Sim B.S itkin, Colin Camerer (1998) ${ }^{[1]}$,says social integration is the process of human social integration. TongShiQing (1999) ${ }^{[2]}$ think social integration refers to the different factors in the adjustment and coordination of social contradictions, conflicts and entanglements, making it the unified process, or result of the system. In the process, from social each phase and related units, through mutual adaptation, and keep the same code of conduct and to unite as one, forming a balanced system . The central defender (2001), ${ }^{[3]}$, argues that social integration refers to the exchange ofexchanges between the various parts of the social system that can be orderly rather than full of obstacles and conflicts. Guo-rong Yang (2001) ${ }^{[4]}$ 
specifically expounds the role of moral in social integration, analyzed the moral consciousness, moral ideal and moral ideas and identity in the preservation of social system, and the code of ethics for the maintenance of social order and disorder, the anomie of inhibition. Hang-sheng zheng $(2003)^{[5]}$ think that a society's social integration of different factors, some integrated into a harmonious and unified process of society as a whole, also known as social integration. Eastern cheng $(2004)^{[6]}$ to integrate social understanding of different factors in the adjustment and coordination of social contradictions and conflicts and entanglements, making it the unified process, or result of system. Juli (2005) ${ }^{[7]}$ believes that social integration is, in essence, the convergence and identity of the conscious mind.

Can be seen from the above, at present scholars mainly methods and perspective of sociology study of social integration, social integration have been the subject of attention, but how to comprehensive study from the interdisciplinary perspective, to be further discussed; This article attempts to apply social integration to the research of senior management teams. Hambrick \&mason (1984) put forward the high-level team theory, which opens the way for a team to look at the corporate leadership. Every executive in a business has a mature cognitive system, and high levels of executive team work produce high-quality decisions. Enterprise management practice, organizational decisions are decided jointly by the team members, eventually executives need to reach a consensus, and individuals from team to team consensus requires effective social integration. O 'reilly, Caldwell \& Barnett (1989) think social integration is a multidimensional phenomenon, which reflect the appeal for the team, satisfaction between team members, as well as the social between team members. Hambrick (1994) .

Puts forward the concept of integration, emphasizing the measured by three dimensions team integration level: team cooperation level, quality and quantity of information exchange, collective decision-making level. Hambrick stressed that the social integration includes team members positive social, but more emphasis on team members each other emotional identity, of belonging, and behavior to integrate more emphasis on behavior driven and result oriented.

Combed the social integration in the sociology research above, the experts define the difference of social integration, are only different Angle of view, basically from the perspectives of behavior, values and consciousness emphasizes the integration of social problems. Combining the senior management team of social integration research, this paper argues that senior management team of social integration is embodied in social capital integration level, emotional conflicts integration level, information exchange, collective decision-making level and the team cooperation level in five aspects.

\section{Details of Social Integration of Top Management Teams}

\section{Social Capital Integration}

At present, scholars at home and abroad are concerned about enterprise social capital, and ignore the social capital of entrepreneurs. If you ignore the social capital at the top of the enterprise, it ignores the key factors in the success of the enterprise, will not be highlighted as the enterprise top management team social networks and social capital irreplaceable role for the enterprise development. Foreign scholars more attention to entrepreneurs' social networks, less discussed social capital, Westlund considered entrepreneurs' social capital and open up new ways such as, created a new enterprise together and solve the social problems. Shi Xiuyin domestic scholars think that entrepreneurs as enterprises and the key link of social environment, must be able to obtain the required for the enterprise of government administration and legal resources, production and 
management resources, management and business resources, spiritual and cultural resources, and other resources. This article compared the view that jia miao miao (2009), she thinks that enterprise top management team social capital refers to the embedded within the team members in social networks, a resource interaction ability, it will affect the action of the individuals in the network. Senior management team of network relations ability has an impact not only the enterprise initial or special period, in fact, in every stage of development of enterprise top management team through social networks built up social capital have a direct impact on enterprise performance. Building enterprise senior management team of the integrated mechanism of social capital, a scattered in various executives integrate internal social capital into the senior management team of social capital is the source of enterprise competitive advantage.

\section{Emotional Conflict Integration}

Since the 1990s, the inner workings of senior management teams, especially in conflict, have been noticed by researchers. As Amason (1996) suggests that emotional conflict and decision performance have negative consequences; Simons et al. (2000) found that trust in the team played a negative role in the relationship between cognitive conflict and emotional conflict; Wang guofeng et al. (2007) found that a sense of ownership in the executive team is conducive to reducing emotional conflict. Liu jun et al. (2008) found that the compromise of senior management team was able to restrain the negative impact of emotional conflict. From the point of the present study, the views of the scholars generally consistent, senior management team of emotional conflict is negatively related to the enterprise performance, enhance the sense of belonging of executives, team identity was beneficial to the improvement of the senior management team of emotional conflicts integration level.

\section{Information Exchange}

The establishment of internal communication mechanism within the senior management team is a guarantee of the quantity and quality of the information exchanged. Executives not only need to build and perfect formal communication systems, but also avoid the complexity of the communication hierarchy, which makes organizational communication institutionalized and formalized. Both the communication frequency and the quality of communication are both grasped and the hands are hard, so that the quantity and quality of the information exchange can be improved.

\section{Collective Decision-making}

The main form of performance of senior management team is decision quality, and the strategic decision is the result of the combination of enterprise, enterprise's environment and business executives. In a stable environment, the enterprise can be run according to the conventional process, established conventions, but in an uncertain environment, enterprises are faced with the problem of the unstructured, it is the key executive decision-making capacity. Hambrick (2007) points out that the perception of members in different areas of the senior management team is more comprehensive than that of the CEO, making the decision more reasonable.

\section{Team Work}

The team work model has greatly promoted the performance of enterprises and has been adopted by many enterprises. The senior management team, as a special team, has the scarcity and irreplaceability, and determines the development of the enterprise. Teamwork requires integration of team members all the resources and knowledge, continuously eliminate all discord and injustice, let team members voluntary cooperation, senior management team will be the source of enterprise sustained development power. 
Anyhow, senior management team level of social integration and enterprise performance were positively correlated relationship, enterprise must from the social capital, emotional conflict, information exchange, collective decision-making and team efforts to the five aspects, enhance the level of senior management team of social integration.

\section{STUDY THE SOCIAL INTEGRATION MODEL OF TOP MANAGEMENT TEAM}

Abroad study surrounding of nearly 20 years of senior management team characteristics and operation process, from 1984 to mid - 90 - s, a number of studies have focused on the analysis of the senior management team members demographic characteristics, that can be substituted for demographic characteristics of the cognitive and attitude to predict subjective process characteristics, such as executive team performance. This stage research emphasis on the objectivity of demographics variables and the advantage of simplicity, attaches great importance to the demographic characteristics of the theory of organization performance prediction, but ignoring the theoretical interpretation of senior management team characteristics influence organization performance. This article is to make up for the senior management team theory, through the literature research, this paper discusses the senior management team part of the social integration construct, build out of the top management team social integration research model as shown in fig1:

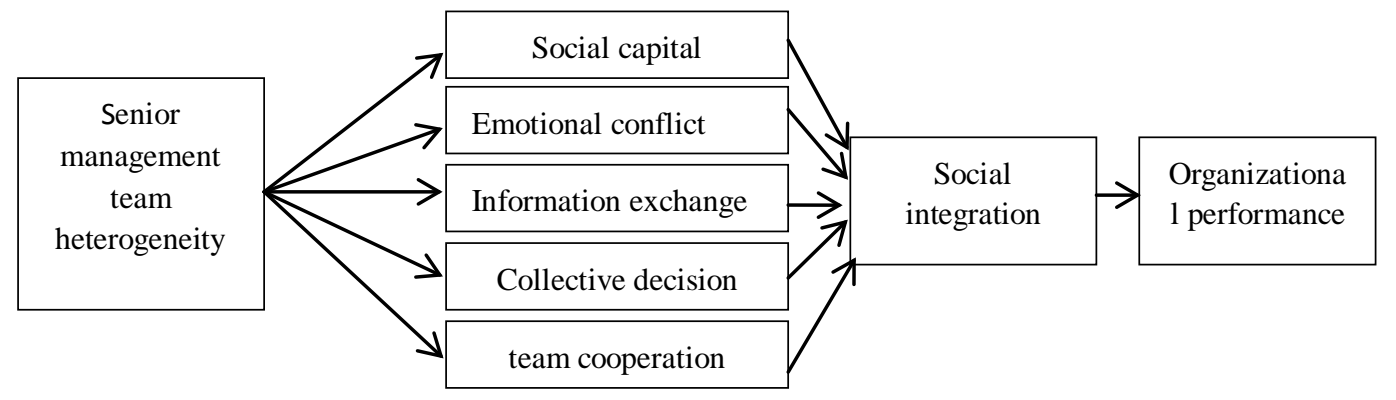

Fig1 high-level management team's social integration research model

Senior management team is made up of different age, tenure, education background and different psychological characteristics of people, they are due to different background, experience and cognition of things are different, so the top management team heterogeneity. The heterogeneity of the senior management team is a double-edged sword, and the team's high level of resources is conducive to the improvement of the organization's performance, while the negative effect is generated. To solve this problem, this paper argues that the senior management team should be the social capital integration, integration of emotional conflicts, information exchange, collective decision-making level, teamwork this five aspects to enhance the level of social integration and social integration level is higher, the more conducive to organizational performance.

\section{References}

[1]Dennise M. Rousseau,Sim B. Sitkin,Colin Camerer. Not So Different After All: A crossdiscipline View of Trust[J]. Academy of Management Review,1998(03).

[2]Hambrick DC, Mason PA. Upper echelons: The organization as a reflection of its top managers[J],Academy of Management Review,1984,9(2): 193-206

[3]Finkelstein, S., \& Hambrick, D.C. (1996). Strategic Leadership: Top Executives and Their Effects on Organizations. Minneapolis/St Paul: West Publishing Company. 
[4] O'Reilly III, C. A., Caldwell, D. F.,\& Barnett,W.P.. Work Group Demography, Social Integration, and Turnover. Administrative Science Quarterly,1989,34(1),21-37.

[5] Hambrick D C. Top Management Groups: A Conceptual Integration and Reconsideration of the "Team" Label[M]B M CUMMINGS . Research in Organizational Behavior. Greenwich,CT: JAI Press,1994(16): 171-213.

[6] Amason A C. Distinguishing the Effects of Functional and Dysfunctional Conflict On Strategic Decision Making: Resolving a Paradox for Top Management Teams[J]. Academy of Management Journal,1996,39(1): 123-148.

[7]Simons T L, Peterson R S. Task Conflict and Relationship Conflict in Top Management Teams: The Pivotal Role of Intragroup Trust[J]. Journal of Applied Psychology,2000,85(1): 102-111.

[8]Hambrick, D. C. Upper Echelons Theory: An Update. The Academy of Management Journal,2007,32(02),334-343. 